13. Muravskaya O. (2017) Eastern Christian paradigm of the european culture and music XVIII-XX century: monograph. Odessa, Astroprint [in Russian].

14. Oleynikova Yu. (2010) Biedermeier and his manifestations in vocal music of XIX-XX century. Abstract to candidate's thesis/ Odessa [in Ukrainian].

15. Solovcova L. (1986) G. Verdi.Moscow, Muzyka [in Russian].

Стаття надійшла до редакції 13.12.2017

УДК $782.082+786.2$

DOI 10.31723/2524-0447-2018-26-172-185

\author{
Чжоу Дапин \\ https://orcid.org/0000-0002-6112-4862 \\ Лешанский педагогический университет, \\ соискатель кафедры теории музыки и композиции
}

Одесской национальной музыкальной академии им. А. В. Неждановой 563688385@qq.com

\title{
ЖАНРОВЫЕ ИСТОКИ МУЗЫКАЛЬНОЙ ОБРАЗНОСТИ ФОРТЕПИАННЫХ ПОЛИФОНИЧЕСКИХ ЦИКЛОВ ХХ ВЕКА
}

Цель статьи - определить теоретические предпосылки изучения образного содержания полифонических ииклов в фортепианной музыке ХХ века. Методология. Исследование опирается на традиционный музыковедческий метод жанрово-стилевого анализа, который позволяет обнаружить связь жанровой природы музыкального языка с образным содержанием музыкального произведения. При рассмотрении фортепианного полифонического цикла в творчестве композиторов ХХ века этот метод дает возможность определения жанрового стиля как компонента художественной идеи малого иикла «прелюдия-фуга». Научная новизна состоит в уточнении метода жанрово-стилевого анализа произведений современной музыки и подготовке оснований для построения методики освоения студентами-пианистами образного смысла полифонических циклов современной фортепианной музыки. В работе обсуждаются жанровые истоки музыкальной образности полифонических произведений циклической формы, представления интерпретаторов и слушателей об их художественно-образном содержании, возможность адекватного понимания формы и содержсания музыкальной традиции полифонической фортепианной музыки. Такой подход рассматривается как целесообразный при изучении современного музыкального репертуара, в особенности произведений полифонического цикла в творчестве ведущих композиторов ХХ века. Выводы: жанровая образность музыкального произведения представляет собой важнейший компонент целостного художествен-

(C) Чжоу Дапин, 2018 
но-образного содержания циклического инструментально-полифонического опуса и может служить опорой для построения исполнительской концепции произведения. Жанровая природа музыкально-интонационных средств обнаруживается в самых ранних образцах фортепианного полифонического иикла. Это качество сохранилось и в произведениях композиторов ХХ века, что позволяет ставить вопрос об определенном принципе композиторской поэтики. Жанровые истоки музыкальной образности играют важную роль при изучении прелюдий и фуг современных композиторов будущими пианистами (в частности китайскими студентами). Они значительно облегчают осознание художественной идеи пьесы иикла, являются ключом к пониманию образного содержания музыки и имеют большой педагогический потенциал в решении задачи освоения европейской музыкальной культуры.

Ключевые слова: жанр, жанровый стиль, жсанровая атрибутика, музыкальный образ, музыкальное содержание, музыкальная выразительHocmb.

Zhou Daping, degree-seeking student of the department of music theory and composition of Odessa National A. V. Nezhdanova Academy of Music cles

Genre sources of musical imagery of twentieth century piano polyphonic cy-

The purpose of the article is to determine the theoretical prerequisites for studying the imagery content of polyphonic cycles in the piano music of the twentieth century. The methodology. The research is based on the traditional musicological method of genre-style analysis, which allows us to discover the connection between the genre nature of a musical language and the imagery content of a musical work. When considering the piano polyphonic cycle in the works of composers of the twentieth century, this method makes it possible to determine the genre style as a component of the artistic idea of the small cycle «prelude-fugue». Scientific novelty lies in the refinement of the method of genre and style analysis of contemporary music and the preparation of the grounds for constructing a methodology for mastering the imagery meaning of polyphonic cycles of modern piano music by piano students. The genre sources of the musical imagery of polyphonic works of cyclic form, the ideas of interpreters and listeners about their content, the possibility of an adequate understanding of the form and content of polyphonic piano music are discussed. This approach is considered as appropriate in the study of the modern musical repertoire, in particular - the works of the polyphonic cycle in the works of leading composers of the twentieth century. Conclusions: the genre imagery of a musical work is an important component of the holistic artistic-imagery content of a cyclic instrumental polyphonic opus and can serve as a support for the construction of the performance concept of the work. The genre nature of musical means is found in the earliest samples of the piano polyphonic cycle. This quality has been preserved in the works of composers of the twentieth cen- 
tury, which allows us to raise the question of a certain reception of composer poetics. Genre sources of musical imagery play an important role in studying preludes and fugues of contemporary composers by future pianists (in particular Chinese students). They greatly facilitate the realization of the artistic idea of the cycle playing, are the key to understanding the imagery content of music and have great pedagogical potential in solving the problem of mastering in European musical culture.

Keywords: genre, genre style, genre attributes, musical image, musical content, musical expressiveness.

Чж⿻上 Дапін, здобувач ступеня кандидата мистецтвознавства кафедри теорії музики та композиції Одеської національної музичної академії імені А. В Нежданової

Жанрові витоки музичної образності фортепіанних поліфонічних циклів ХХ століття

Мета статті - визначити теоретичні передумови вивчення образного змісту поліфонічних ииклів у фортепіанній музиці ХХ століття. Методологія. Дослідження спирається на традиційний музикознавчий метод жанрово-стильового аналізу, який дозволяє виявити зв'язок жанрової природи музичної мови з образним змістом музичного твору. При розгляді фортепіанного поліфонічного ииклу у творчості композиторів ХХ століття цей метод дає можливість визначення жанрового стилю як компонента художньої ідеї малого циклу «прелюдія-фуга». Наукова новизна полягає в уточненні методу жанрово-стильового аналізу творів сучасної музики та підготовиі підстав для побудови методики освоєння студентами-піаністами образного сенсу поліфонічних циклів сучасної фортепіанної музики. У роботі обговорюються жанрові витоки музичної образності поліфонічних творів циклічної форми, уявлення інтерпретаторів і слухачів про їх художньо-образний зміст, можливість адекватного розуміння форми і змісту музичної традицї̈ поліфонічної фортепіанної музики. Такий підхід розглядається як доцільний при вивченні сучасного музичного репертуару, особливо - творів поліфонічного циклу у творчості провідних композиторів ХХ століття. Висновки: жанрова образність музичного твору являе собою найважливіший компонент цілісного художньо-образного змісту ииклічного інструментально-поліфонічного опусу і може служити опорою для побудови виконавської конщепції твору. Жанрова природа музично-інтонаційних засобів виявляється вже у найбільш ранніх зразках фортепіанного поліфонічного циклу. Ця якість збереглася і в творах композиторів ХХ століття, що дозволяє ставити питання про певний принцип композиторської поетики. Жанрові витоки музичної образності грають важливу роль при вивченні прелюдій і фуг сучасних композиторів майбутніми піаністами (зокрема китайськими студентами). Вони значно полегшують усвідомлення художньої ідеї п'єси циклу, є ключем до розуміння образного змісту музики і мають великий 
педагогічний потенціал у вирішенні завдання освоєння європейської музичної культури.

Ключові слова: жанр, жанровий стиль, жанрова атрибутика, музичний образ, музичний зміст, музична виразність.

Актуальность темы. В современном музыкальном образовании фортепианная музыка XX века является тем пластом музыкального репертуара, который представляет значительные трудности для студентов в силу новизны, недостаточной освоенности и понятности ее музыкального языка, а также ее эстетических и философско-мировоззренческих истоков. Отказ от языковых норм музыкального искусства, сложившихся в классическую эпоху, открытие новых музыкально-выразительных средств в творческих опытах композиторов рубежа XIX-XX веков и утверждение принципа неограниченной свободы индивидуально-композиторского мышления в последующие десятилетия обусловили радикальное обновление как формы (фонологии, морфологии, лексики, синтаксиса, композиции), так и содержания музыкальных произведений.

Особую сложность для понимания и творческой интерпретации представляют фортепианные произведения полифонических жанров, в первую очередь в жанре микроцикла, включающего наряду с фугой прелюдию или пьесу иного типа. Этот вид полифонической композиции, сложившийся на протяжении XVII-XVIII веков (в эпоху барокко), пережил подлинный ренессанс в творчестве композиторов XX столетия. К знаменательным сочинениям жанра относятся фортепианные полифонические циклы И. Асеева, В. Бибика, В. Задерацкого, К. Караева, А. Караманова, П. Хиндемита, М. Скорика, С. Слонимского, М. Тица, А. Хачатуряна, Д. Шостаковича, Р. Щедрина и др.

Исполнение полифонических циклов составляет трудную задачу для пианиста-интерпретатора. Сложности исполнения полифонической музыки связаны с особыми требованиями к технике пианистического туше, подчиненного правилам четкой и выразительной артикуляции и фразировки элементов многоголосной фактуры, с выполнением точно рассчитанного темпорального плана звукового воплощения композиции, с обеспечением необходимого баланса между однородностью и обновлением характера звучания и т. д. Эти исполнительские задачи особенно трудны для китайских студентов, слуховой опыт которых основан преимущественно на одноголосной и гетерофонной музыке, а знание фортепианной музыки опирается 
главным образом на классические и романтические произведения гомофонно-гармонической фактуры. Именно поэтому им так трудно дается освоение фортепианных полифонических произведений. Еще более трудной задачей для будущих пианистов из Китая и других азиатских стран является интерпретация полифонической музыки композиторов XX века, эстетические качества и художественная семантика которой им не вполне понятны.

В этой ситуации существенными оказываются жанрово-стилевые свойства музыкальной формы, которые практически всегда могут быть обнаружены в полифонических произведениях, независимо от степени новизны и сложности их музыкального языка. Поэтому целесообразным представляется обращение будущих профессиональных пианистов в процессе обучения к тем образцам прелюдий и фуг, которые имеют яркую и понятную образность, связанную с жанровостилевой определенностью.

Научная новизна состоит в уточнении метода жанрово-стилевого анализа произведений современной музыки и подготовке оснований для построения методики освоения студентами-пианистами образного смысла полифонических циклов современной фортепианной музыки.

Цель статьи - определить теоретические предпосылки изучения образного содержания полифонических циклов в фортепианной музыке XX века. Исследование опирается на традиционный музыковедческий метод жанрово-стилевого анализа, который позволяет обнаружить связь жанровой природы музыкального языка с образным содержанием музыкального произведения. При рассмотрении фортепианного полифонического цикла в творчестве композиторов $\mathrm{XX}$ века данный метод дает возможность определения жанрового стиля как компонента художественной идеи малого цикла «прелюдия-фуга».

Объект исследования - фортепианный полифонический цикл в творчестве композиторов XX века. Предмет исследования - жанровые аспекты художественной образности полифонических произведений циклической формы.

Анализ исследований и публикаций. Теория музыкального жанра является одним из базовых направлений музыковедения, фундаментальные ее разработки содержатся в трудах Е. Назайкинского, М. Арановского, Б. Асафьева, А. Альшванга, Л. Мазеля, В. Цуккермана, В. Холоповой, В. Медушевского, А. Сохора, Е. Зинкевич, 
В. Москаленко, О. Самойленко, С. Шипа и др. Вопросам жанровой и стилевой специфики фортепианной музыки XX века посвящены исследования Л. Гаккеля, М. Смирнова, О. Собакиной, разделы хрестоматийной «Истории фортепианного искусства» А. Алексеева. Сведения о новаторских открытиях в фортепианной музыке современных композиторов Европы и Америки содержатся в монографии С. Павлишин. Однако перечисленные авторы специально не исследовали жанровые аспекты семантики фортепианных произведений. Такого рода вопросы обсуждаются лишь фрагментарно.

Жанровые аспекты фортепианных полифонических циклов XX века освещаются в монографиях, посвященных творчеству того или иного композитора - Д. Шостаковича (А. Должанский), Р. Шедрина (В. Холопова), П. Хиндемита (Т. Левая, О. Леонтьев), В. Бибика (Е. Зинкевич, А. Мизитова, И. Иванова, С. Мирошниченко) и др. В данном случае жанровость рассматривается в широком контексте индивидуального композиторского стиля, традицинных жанровых структур, новаторского подхода к жанровым канонам и нормам.

Основное содержание. Интерпретация произведений полифонических жанров, в частности полифонических циклов и микроциклов - одна из самых сложных задач музыкально-исполнительского искусства. Подготовка профессионального пианиста к ее решению также составляет значительную методическую трудность. Значительная сложность исполнительской и педагогической задачи заключается в том, что полифонические произведения обычно лишены какойлибо конкретной образно-содержательной программы, способной направить восприятие слушателя и исполнителя. Очень редко нотный текст полифонических пьес содержит программный заголовок, авторское посвящение или развернутые словесные ремарки автора относительно характера исполнения. Как правило, единственными образно-семантическими указателями служат жанровые названия («жанронимы» по С. Шипу): фуга, канон, прелюдия, интерлюдия, постлюдия и др.

Сразу же необходимо заметить, что все подобные лексемы неоднозначны. Они служат обозначениями не только жанров, но также композиционных типов и принципов формообразования. «Фуга», к примеру - это, во-первых, обозначение принципа сочинения имитационно-полифонической ткани, который начал разрабатываться еще в эпоху Возрождения. Во-вторых, это обобщенное название целого ряда типичных композиционных структур (например: фуга 
без интермедий, стреттная фуга, двойная фуга и т. д.). Наконец, этот специальный термин трактуется как жанровое имя инструментальной или вокальной пьесы, имеющей определенные формальные признаки фактурного и композиционного устройства. Вследствие этой множественности значений жанронимы полифонических пьес мало способны прояснять и конкретизировать для пианиста-интерпретатора художественно-образный смысл последних.

Какие же подходы к постижению художественно-образной семантики конкретных полифонических произведений являются в подобных условиях наиболее целесообразными и могут быть рекомендованы молодым пианистам? Относительно простым и одновременно эффективным способом приближения студента к осмыслению и последующему звуковому воплощению образного содержания полифонического произведения является направление его слухового внимания и интеллектуальных усилий на жанрово-стилевые свойства формы и осознание ее жанровой образности. «Все, что вытекает от жанровости (а музыки без жанровой направленности, жанровых коннотаций попросту не существует), - отмечает Б. Иоффе, - при семантизации непроизвольно связывается с «реальной жизнью», обществом, историей, биографическими категориями и так далее, едва ли не решающую роль в этом процессе играет укорененность слушателя в актуальном культурном контексте [3, 5].

Жанр как основная категория музыкального искусства является постоянным объектом музыковедческих дискуссий, направленных на определение его сущности и основных функций. При всей разности точек зрения на жанровую природу музыки существует все же общий момент, который признается большинством историков и теоретиков музыкального искусства: музыкальный жанр изначально связан с конкретной жизненной ситуацией, с конкретным жизненным контекстом, определившим его функцию и назначение в жизни человека. Именно поэтому музыковеды называют жанр «жизненной осью» музыки $[8,218]$, «генетической структурой», отражающей конкретный «ситуативный комплекс» [6].

В дифференциации музыкальных жанров музыковеды опираются обычно на содержательный и функциональный критерии оценки произведений, т. е. на конкретный тип образности, закрепившийся за тем или иным жанром, а также на представление о его месте и роли в музыкальной практике общества (В. Цуккерман, А. Сохор). Функциональная сторона жанра может рассматриваться в качестве 
своеобразного словаря - некоторого набора «лексем», которые специфичны для данного жанра и сохраняются за ним в процессе его исторической эволюции (В. Холопова).

В соответствии с эмпирическими представлениями о массиве музыкальных жанров Д. Кабалевский в своей педагогической концепции определил наличие в каждой культуре трех жанровых архетипов, по его выражению - «трех китов»: песни, танца и марша, на которых «...держится вся музыка от истоков своих и до сегодняшнего дня» $[3,4]$. В данном случае речь идет о так называемых первичных жанрах, возникновение которых связывается обычно с наиболее очевидными потребностями человека - личностными и коллективными. Е. Назайкинский подчеркивает, что они «...вызываются самой жизнью, социальными установлениями, традициями, обычаями» [6, 135]. В работах Е. Назайкинского мы находим очень важную мысль, имеюшую прямое отношение к жанровым истокам музыкальной образности: «...при переносе обиходной, бытовой музыки в концертный зал эта память - память о первичных ситуациях - оказывается важным с художественной точки зрения содержательным, смысловым компонентом. Но даже если таких следов нет, музыкальный материал жанра в сознании слушателей, исполнителей, участников коммуникации вступает в прочную ассоциативную связь с жанровой ситуацией. И тогда, уже в других обстоятельствах и условиях, даже в другом историческом контексте, он начинает выполнять функцию напоминания о той прежней ситуации и вызывать определенные, окрашенные воспоминаниями эстетические переживания» $[6,136]$.

Таким образом, в музыкальном произведении слух обнаруживает свойства, стороны, отдельные элементы музыкальной формы, обладающие устойчивой образно-содержательной и музыкально-языковой типичностью, закрепленной в общественном сознании. Эта типичность обычно и вызывает конкретные смысловые ассоциации, связанные с конкретикой музыкального содержания. Отсюда вытекает и широко используемое понятие «жанрового стиля», соединяющего в себе особенности музыкального языка и образно-содержательные аспекты музыкального произведения. Как указывает Е. Назайкинский, «жанровый стиль распознается по двум признакам - собственно личностному и ситуационному» [6, 133].

Следовательно, одна из задач музыканта-исполнителя - уметь распознать жанр, опираясь на его стилевые признаки в форме, и осмыслить его отношение к контекстовым стилевым средствам про- 
изведения, создающим «ситуационные» образные смыслы. Такой подход составляет значительную трудность для художественно-образной интерпретации всей фортепианной полифонической музыки.

Особую остроту проблема понимания и воплощения образного смысла полифонических опусов приобретает при обращении студентов-пианистов к произведениям композиторов XX века. Известная свобода современного композиторского мышления во многом «затушевывает» отмеченные инвариантные показатели жанра и жанрового стиля (что часто бывает обусловлено тенденцией к жанровому синтезу и полистилистике в музыкальном творчестве). Их узнавание часто затруднено из-за сложности музыкального языка, нетрадиционной, неклассической логики построения композиции и т. п.

Можно заключить, что будущий пианист (особенно это касается студентов из Китая и других стран Азии) должен основательно познакомиться со стилевыми средствами полифонических жанров европейской музыки. Уяснение стилевых свойств музыкального произведения (его жанрового истока и эволюции, а главное - порождающего жанр «ситуативного комплекса») значительно облегчает понимание образного содержания музыки. Жанровая определенность формы является важнейшим выразительным средством музыкального искусства, а в классических образцах полифонического цикла у И. С. Баха она присутствует очень часто, о чем не раз писали исследователи его творчества. Причем И. С. Бах был далеко не первым в этом отношении. Подобный прием применялся его предшественниками и старшими современниками. Ярко выраженная жанровая образность присутствует в сочинениях Дж. Фрескобальди, Г. Шютца, Д. Букстехуде, Г. Генделя и многих других композиторов. В их клавирных и органных произведениях часто присутствуют признаки как первичных жанров (танцев, песен, маршей, военной музыки), так и вторичных, т.е. сформированных в профессиональной композиторской практике (ария, хорал, мадригал, мотет). Как написала Т. Ливанова, Бах и Гендель владели «...почти всем достоянием жанровых выразительных средств» своего времени $[5,186]$.

То есть речь идет о распространенной и привычной поэтике музыкального творчества, актуальной и для последующих эпох, смысл которой заключается в конструировании композитором художественной идеи произведения с помощью устойчивых типовых показателей того или иного жанра, вызывающих у слушателя достаточно определенные образно-содержательные ассоциации. 
Так, например, в прелюдиях и фугах ХТК И. С. Баха исследователи отмечают совершенно конкретные жанровые признаки танцев того времени: куранты (Прелюдия F-dur, II том [2]); сицилианы, аллеманды, пасторали, колыбельной (Прелюдия E-dur, I том); сарабанды (Прелюдия es-moll, I том). Также выявлены жанрово-стилевые признаки: плача-причитания (Прелюдия fis-moll, II том); речитатива-декламации (Прелюдия D-dur, II том; фуга D-dur, I том); хорала (Прелюдии es-moll, b-moll I том). Б. Яворский трактовал глубинное религиозно-сакральное содержание полифонического цикла ХТК И. С. Баха, опираясь на символику, присущую старинным музыкальным жанрам (известно, что исследователь считал этот цикл «художественным толкованием Священного Писания»). Так, ритм сарабанды (изначально - не танца, но торжественного скорбного шествия) Б. Яворский связывал с образом (литературным и иконографическим каноном) «Снятия с креста», а ритм сицилианы (изначально - пасторального танца) - с Рождеством Иисуса Христа.

В музыкальном тематизме пьес ХТК стилевая определенность танцев и других жанров представлена не полным комплексом интонационно-выразительных средств: композитор воспроизводит лишь узнаваемые типы движения (мелодического и ритмического) и фактуры, присущие тем или иным жанровым единицам. Однако возникающие ассоциации с тем или иным жанром, с его функцией в обыденной жизни «проливают свет» и на образное содержание музыки полифонического цикла, помогая исполнителю и слушателю точнее понять композиторский замысел. «Через жанр, явственно просвечивающий сквозь обобщенно-полифоническую форму, Бах выражает определенное музыкальное и философское содержание», - пишет Носина [7, 69]. И далее: «... абстрагированная, очищенная от бытового жеста, музыкальная мысль приобретает большую материальную наполненность, вызывает ассоциации зримой пластики. Идея движения получает образную конкретность жанрового выражения» [7, 71].

Тематизм ХТК глубоко связан также с протестантским хоралом. Текст хоральных мелодий был известен каждому члену протестантской конгрегации. Так что мелодии прелюдий и фуг, служащие темами полифонических опусов, вызывали совершенно конкретные образы, мысли, эмоции и ассоциации религиозного плана. Цитирование протестантского хорала было широко распространено в светской камерно-инструментальной музыке того времени. C XVII века в Германии распространены домашние хоральные сборники, в кото- 
рых содержались как песнопения церковного обихода (хоралы), так и духовные арии с сопровождением, которые предназначались для домашнего исполнения. Последние отличались гораздо более выраженной эмоциональностью «озвучивания» религиозных текстов, аффектированным стилем музыкального языка $[1,46]$. Так осуществлялась связь музыки церковной с жизненно-бытовым контекстом.

Творческий принцип И. С. Баха и композиторов-современников нашел свое продолжение и в последующие эпохи. Он нашел свое воплощение в самых известных полифонических циклах композиторов XX века: Д. Шостаковича, П. Хиндемита, Р. Щедрина, М. Скорика и др. Жанровые истоки музыкальной образности полифонических композиций этих композиторов хорошо заметны. Некий образносодержательный «заряд» содержится уже в самих жанровых определениях пьес цикла - прелюдии и фуги, которые обращены к давним традициям европейской инструментальной музыки и, тем самым, несут устоявшиеся в веках представления о назначении и особенностях каждой из пьес цикла.

В некоторых случаях композиторы сохраняют баховский принцип организации прелюдий и фуг (Д. Шостакович, Р. Щедрин, М. Скорик), некоторые - строят свой цикл в ином ключе, обусловленном оригинальной концепцией ладотональных отношений (П. Хиндемит). Однако все композиторы сохраняют главную жанровую идею микроцикла прелюдии и фуги, соединяющего пьесу свободного, импровизационного типа со строго организованной, мастерски рассчитанной композицией. В каждом из циклов, написанных в XX веке, в различной мере, но всегда обнаруживается некая жанрово-стилевая определенность музыкальной формы прелюдий и фуг, которая служит слушателям и исполнителям основным ориентиром осмысления художественно-образного содержания.

Так, например, в «24 прелюдиях и фугах» Д. Шостаковича широко представлены жанровые стили песни, хорала и скерцо. Эти жанры воспринимаются как знаки конкретной образности, связанной как с национально-культурным контекстом (русская песня), религиозно-этическим смыслом (хорал), обобщенным типом музыкального движения (скерцо). У Р. Щедрина выразительные монологические темы фуг также обладают теми или иными жанровыми признаками: особенно ярко представлены те, которые связаны с фольклорными традициями русской культуры - песня, частушка, плач. В цикле прелюдий и фуг М. Скорика, наряду с хоральностью, песенностью 
и другими жанрово-стилевыми признаками, ярко представлена стилистика колокольного звона. Широкое семантическое поле этого достаточно распространенного в инструментальной музыке жанрового стиля отражает смыслы, сложившиеся в различных культурных традициях. Семантической доминантой этого круга жанрово-стилевых средств является первичное значение колокольного звона (греческое калео, латинское каlare означает созывать), обусловленное сигнальной функцией колокола. Звучание колокола связано с очень разнообразным содержанием музыки: это и торжественный («красный») звон, возвещающий какое-либо важное событие в жизни народа, и тревожный набат, и праздничные перезвоны церковных колоколов, и похоронный звон. Эти образы отражают реалии человеческой жизни: «единение и гражданский долг, независимость и величие государства» [4, 59], религиозная идея, или трагические переживания, связанные с уходом из жизни. В любом случае, обращаясь к жанрово-стилевым средствам колокольного звона, М. Скорик воплощает в своем полифоническом опусе понятные каждому человеку художественные образы, неразрывно связанные с жизнью людей.

Цикл «Ludus tonalis», созданный П. Хиндемитом в честь 200-летия со дня завершения Бахом II тома ХTK, представляет собой 12 трехголосных фуг, между которыми расположены интерлюдии. Цикл обрамляется прелюдией и постлюдией. Фуги следуют, подчиняясь тональной логике, а именно - порядку убывающего акустического родства по отношению к главной тональность (До). Интерлюдии выполняют в цикле связующую функцию, обеспечивая переход от тональности предыдущей фуги в тональность последующей. Музыкальный язык цикла «Ludus tonalis», использованные интонационные средства не позволяют сразу выделить какие-либо определенные образные смыслы. Атональное развитие музыкального материала и сложнейшая полифоническая техника, которой в совершенстве владел П. Хиндемит, придают этой музыке абстрактный характер, вызывающий ассоциацию с нефигуративной живописью или современной урбанистической архитектурой.

Вместе с тем, при более внимательном рассмотрении, уже в первой пьесе цикла - «Прелюдии» - обнаруживаются жанрово-стилевые черты, которые проясняют образное наполнение произведения и облегчают размышления о смысле этой музыки. Тип фактуры и ритмическая организация тематизма здесь представляют токкатный стиль, который был одним из самых распространенных в органной и 
клавирной музыке XVI-XVIII столетий. Токката как жанр сложилась как вступительная часть инструментального цикла - виртуозная пьеса в быстром темпе, с четким равномерным движением короткими длительностями. Как правило, токкаты писалась в свободной импровизационной форме, близкой к прелюдии или фантазии. В «Прелюдии» П. Хиндемита подготовленное мышление различает специфические признаки одной из разновидности токкаты, а именно - toccata cromatica. Композиция токкат данного типа состоит из прелюдийного раздела и ричеркара. Такие токкаты возникли и практиковались в церковном музыкальном обиходе. С их помощью устанавливалась тональность, в которой затем паства исполняла хорал или гимн. Использование стилевых признаков хроматической токкаты связано с положением этой пьесы в цикле: «Прелюдия» настраивает слушателя и исполнителя на восприятие всего цикла, демонстрирует композиторское техническое мастерство и виртуозность исполнителя - качества, генетически присущие инструментальным полифоническим пьесам. Отметим и третий момент, вытекающий из жанровых истоков начальной пьесы «Ludus tonalis» и самым прямым образом влияющий на музыкальную образность. В эпоху Возрождения под токкатой подразумевалась праздничная фанфара для духовых инструментов и литавр, которая использовалась при каких-либо торжественных событиях. Если учесть это обстоятельство, то можно заключить, что «Прелюдия» из полифонического цикла П. Хиндемита может пониматься и как патетическое «возвещение» о торжественном и важном событии. Сегодня мы можем с уверенностью утверждать, что торжество музыкальной логики в этой «игре тональностей» вполне может расцениваться как событие в эволюции музыкального мышления.

Выводы. Обобщая наши рассуждения, мы приходим к выводу, что жанровая образность музыкального произведения представляет собой важнейший компонент целостного художественно-образного содержания циклического инструментально-полифонического опуса и может служить опорой для построения исполнительской концепции произведения. Жанровая природа музыкально-интонационных средств обнаруживается в самых ранних образцах фортепианного полифонического цикла. Это качество сохранилось и в произведениях композиторов XX века, что позволяет ставить вопрос об определенном принципе композиторской поэтики. Жанровые истоки музыкальной образности играют важную роль при изучении прелюдий и фуг современных композиторов будущими пианистами (в частности 
китайскими студентами). Они значительно облегчают осознание художественной идеи пьесы цикла, являются ключом к пониманию образного содержания музыки и имеют большой педагогический потенциал в решении задачи освоения европейской музыкальной культуры.

\section{СПИСОК ЛИТЕРАТУРЫ}

1. Берченко Р. В поисках утраченного смысла. Болеслав Яворский о «Хорошо темперированном клавире». М. : Классика-XXI, 2005. 372 с.

2. Йоффе Б. Иоганн Бах. Хорошо Темперированное Ничто. Ханограф URL: http://khanograf.ru/arte

3. Кабалевский Д. Про трех китов и про многое другое. Пермь: Пермское книжное издательство, 1974. 184 с.

4. Лазутина Т. Колокольность как выражение национального своеобразия русской музыки. Вестник Томского государственного университета. Томск: ТГУ, 2008. № 306 (1). С. 55-61.

5. Ливанова Т. Бах и Гендель. Проблемы стиля. Русская книга о Бахе. М.: Музыка, 1985. С. 183-203.

6. Назайкинский Е. Стиль и жанр в музыке. М.: ВЛАДОС, 2003. 248 с.

7. Носина В. Символика музыки И. С. Баха. Санкт-Петербург, 1997. 93 с.

8. Холопова В. Музыка как вид искусства: учебное пособие. СПб.: Лань, 2000. $320 \mathrm{c}$.

\section{REFERENCES}

1. Berchenko R. (2005). In search of lost meaning. Boleslav Yavorsky on the «Well Tempered Clavier». M.: Classics-XXI [in Russian].

2. Joffe B. Johann Bach. Well Tempered Nothing. Chanograph. URL:http:// khanograf.ru/arte

3. Kabalevsky D. (1974). About three whales and much more. Perm: Perm Publishing House [in Russian].

4. Lazutina T. (2008). Kolokolnost as an expression of the national peculiarity of Russian music. Bulletin of Tomsk State University. No. 306 (1). Tomsk: TSU [in Russian].

5. Livanova T. (1985). Bach and Handel. Problems of style. Russian book on Bach. M.: Music [in Russian].

6. Nazaikinsky E. (2003). Style and genre in music. M.: VLADOS [in Russian].

7. Nosina V. (1997). Symbols of the music of J. S. Bach. Saint-Petersburg [in Russian].

8. Kholopova V. (2000). Music as an art form: a textbook. St. Petersburg : Lan [in Russian].

Стаття надійцла до редакції 22.11.2017 